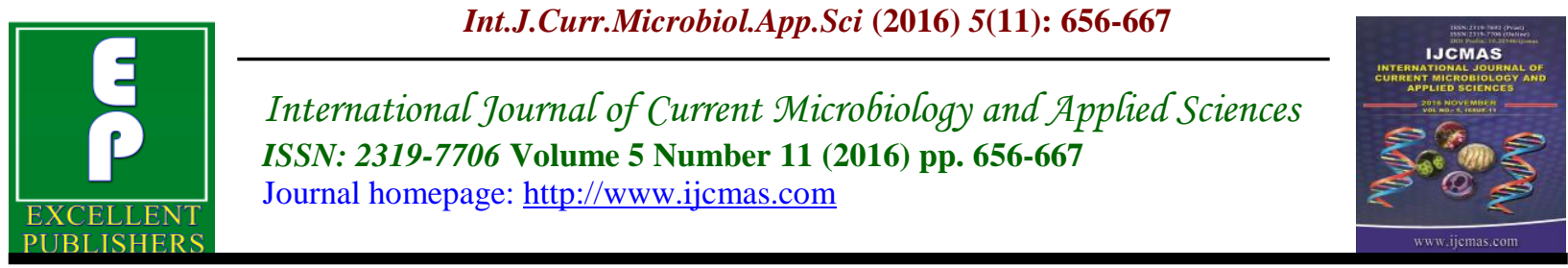

Original Research Article

http://dx.doi.org/10.20546/ijcmas.2016.511.077

\title{
Effect of Phytochemical Fractions of Vernonia amygdalina on Liver of STZ Induced Diabetic Male Wistar Rats
}

\author{
Bob I.A. Mgbeje*, Terungwa A. Kalana, Flora O. Ugoanyanwu and Patrick E. Ebong \\ Department of Biochemistry, Faculty of Basic Medical Sciences, University of Calabar, \\ P.M.B. 1115, Calabar, Nigeria \\ *Corresponding author
}

Keywords

Diabetes,

Vernonia amygdalina,

Methanol and butanol fractions, hepatoprotection.

Article Info

Accepted:

26 October 2016

Available Online:

10 November 2016

\section{A B S T R A C T}

The aim of the study was to investigate the hepato-protective effect of the phytochemical fractions of Vernonia amygdalina (VA) on Streptozotocin (STZ)induced diabetic albino Wistar rats. Forty eight rats weighing between $140-180 \mathrm{~g}$ were divided into eight groups of six rats each. Groups one and two representing normal control (NC) and diabetic control (DC) received $0.5 \mathrm{ml}$ of dimethylsulphoxide (DMSO). Group three received $5 \mathrm{IU} / \mathrm{kg}$ body weight insulin intraperitoneally and group four received $200 \mathrm{mg} / \mathrm{kg}$ body weight crude VA extract orally. Group five to eight received 30\%, 50\% and 100\% methanol and butanol VA fractions respectively at $75 \mathrm{mg} / \mathrm{kg}$ b.w. The Serum liver enzymes alanine aminotransferase (ALT), aspartate aminotransferase (AST), alkaline phosphatase (ALP) and histology of the Liver were analyzed after 28 days treatment period. The results showed a significant $(\mathrm{P}=0.05)$ increase in the serum ALT, AST, ALP concentrations in diabetic rats relative to NC. The increases were reversed towards normal in 30\%, $100 \%$ methanol and butanol fraction treated groups and crude extract at varying degrees. The butanol fractions, on balance, showed a better overall ameliorative impact than the other fractions. Histological examination of the liver confirmed these results. While Section of the liver of the NC group showed a preserved architecture with abundant cytoplasm and prominent intact nuclei, that of the DC group showed swollen hepatocyte with mild inflammatory infiltrates, vacuolated nuclei with the very eosinophilic cytoplasm showing micro vesicular steatosis. The sinusoid was very dilated and congested. Treatments with the crude extract and fractions showed a restoration of the integrity of the hepatocytes to various degrees reflecting the order of their effect on the liver enzymes. These result showed that VA fractions, like the crude extracts, may be useful in the treatment of liver damage associated with STZ-induced diabetes. From the findings the butanol fraction of VA was more effective in the reversal of diabetes induced hepatotoxicity. The study represents a step towards determining the active principles of VA involved in reversal of diabetes induced hepatotoxicity and ultimately the standardization of the VA plant in diabetes therapy. 


\section{Introduction}

Diabetes mellitus is becoming a major global public health concern. It is estimated that there will be more than 439 million people suffering from diabetes in nearly all countries by the year 2030 (Shaw et al., 2010). Diabetes mellitus is characterized by absolute or relative deficiencies in insulin secretion and/or insulin action associated with chronic hyperglycemia and disturbances of carbohydrate, lipid, and protein metabolism (Wild et al., 2004; ADA, 2005) and if uncontrolled can lead to increased production of free radicals especially reactive oxygen species (ROS) and nitrogen oxygen species (NOS) which may ultimately result in destruction of some vital organs of the body (Halliwell and Gutteridge, 1989; Robertson, 2004; Moussa, 2008). As the current available therapies with synthetic drugs is froth with numerous side effects (Rang and Dale, 1991) current emphasis has shifted to the use of medicinal plants or herbal medicine as the treatment of choice ostensibly because of its little or no adverse effects, easy accessibility and low cost. Moreover, as much as $80 \%$ of the populations in the developing world depend on traditional medicine which makes it a potential tool for primary healthcare delivery (Akerele, 1993; Kunle et al., 2012). One of such plants with promising potentials for the treatment of diabetes is the perennial shrub Vernonia amygdalina.

Vernonia amygdalina, a member of the Asteraceae family, grows widely in tropical Africa and is used variously for nutritional and medicinal purposes. The macerated leaves are used in preparing 'olugbu soup' which is a delicacy among the Igbos of South east Nigeria. The leaf extracts have been reported to possess anti-malarial and anti-cancer activities and to strengthen the immune system through the regulation of many cytokines (Nwanjo and Nwokoro,
2005; Ejere et al., 2015 and references therein). Vernonia amygdalina has also been shown in our laboratory and elsewhere to possess hypoglycemic and hypolipidemic properties, reverse hepatotoxicity (Atangwho et al., 2012; Efiong et al., 2013 and references therein) and reverse the suppressed level of male sex hormones and testicular damage associated with STZinduced diabetes in rats (Asuquo et al., 2010; Mgbeje et al., 2016). While these and other antidiabetic potentials of the plant has been established, it has not been determined, however, which active principle(s) of the plant are responsible for the observed antidiabetic activities. It was as a prelude to this that we started a systematic fractionation of the plant's crude leaf extract and have so far delineated the fractions that reversed hyperglycemia and pancreatic beta cell damage (Ugoanyanwu et al., 2015) and the depressed male sex hormone levels and testicular damage (Mgbeje et al., 2016) in streptozotocin-induced diabetic albino Wistar rats. This study is another attempt to identify which of the plant fraction has the hepatoprotective properties of the plant's leave extract in diabetic rats.

\section{Materials and Methods}

Preparation of plant extract: Vernonia amygdalina (VA) leafs were collected and homogenized as previously described (Ugoanyanwu et al., 2016; Mgbeje et al., 2016). Homogenized VA leaves were extracted using $80 \%(\mathrm{v} / \mathrm{v})$ methanol for $48 \mathrm{hrs}$ at a temperature of $40^{\circ} \mathrm{C}$. The solvent in the filtrate was evaporated using a rotary evaporator.

Fractionation of Crude Extract: This was carried out using column chromatography as previously described (Ugoanyanwu et al., 2016; Mgbeje et al., 2016). The methanol crude extract was chromatographed on silica gel (60-120 mesh size) matrix packed into a 
glass column and eluted successively with butanol, 30\%, 50\% and 100\% methanol.

Experimental Animals and Induction of Diabetes: Forty eight (48) albino Wistar rats weighing between 140-180g were employed in the study. These animals were divided into eight groups of six rats each and treated according to the schedule in Table $1 . \mathrm{LD}_{50}$ was determined as described by Lorke, 1983. Diabetes was induced using $40 \mathrm{mg} / \mathrm{kg} . \mathrm{bw}$ streptozotocin dissolved in $0.1 \mathrm{M}$ sodium citrate buffer $(\mathrm{pH} 4.5)$ as previously described (Ugoanyanwu et al., 2016; Mgbeje et al., 2016).

Measurement of Glucose levels: Glucose levels where measured every four (4) days with the use of anAccu-Check Active glucometer (Accu-Check, Roche Diagnostics, Germany).

Collection of Blood for Analysis of Liver Enzymes: At the end of the 28days experimental period, the animals were fasted for 12 hours, but had free access to water, and then anaesthetized under chloroform vapour and dissected. Whole blood for liver enzyme assays was collected from the heart by cardiac puncture using sterile syringes and needles, put into sterile plain tubes and allowed to clot for two hours. The clotted blood was centrifuged at 3,000 rpm for 10 minutes to recover serum from the clotted cells. The recovered Serum was then stored frozen till required for analysis.

Histopathological Studies: The liver from the anaesthetized rats were surgically removed and immediately blotted using filter paper to remove excess blood. The liver was then immediately fixed in buffered $20 \%$ formaldehyde preparatory to histological processing. The fixed liver tissue slices were mounted onto albumin precoated glass slides and stained using Harry's Haematoxilin and Eosin (Hand E) staining procedures as previously described (Ugoanyanwu et al., 2016). The stained sections were studied under a light microscope at (x400) magnification and images digitalized using an Olympus DP 70 digital camera (Olympus Europe, Hamburg, Germany).

Biochemical Assay of Liver Enzymes: The liver enzymes: Alanine amino transferase (ALT), Aspartate amino transferase (AST) and Alkaline phosphatase (ALP) were analyzed using commercial analytical assay kits from Randox laboratories, Ltd. UK according to manufacturer's protocol.

Statistical Analysis: Data obtained was analyzed using the statistical software package SPSS for windows version 11.0 (SPSS Inc. Chicago). Difference between means were determined using the analysis of variance (ANOVA) and multiple comparison test. Values of $\mathrm{P}=0.05$ were considered to be statistically significant.

\section{Results and Discussion}

Blood glucose changes: The blood glucose changes for the various treatment groups is presented in Figure 1. There was a significant and progressive increase in blood glucose level in the diabetic control group when compared to the normal control. Treatment of the animals with plant crude extract, fractions and standard drug brought about a significant reduction and progressive decrease in the glucose levels when compared to the diabetic control. The reductions in glucose levels by the plant extract and fraction where even better than that of the Insulin group.

Effect of Treatment on Serum Levels of Liver Enzymes: The effect of the various treatments on the serum levels of the liver enzymes, ALT and AST and ALP is shown in Figure 2. Diabetes induction (DC) 
resulted in significant increases in the serum levels of liver enzymes when compared to Normal control $(\mathrm{NC})(\mathrm{P}=0.05)$. Treatment with the crude extracts and fractions of VA resulted in significant reductions in the ALT levels relative to DC in the crude, $30 \%$ and $100 \%$ methanol fractions and butanol fractions with the butanol fraction, among the fractions, showing the highest decrease followed by the $100 \%$ methanol fraction. The reduction by the butanol fraction was better than that of the crude extract. Only the crude extract showed a significant reductionin AST relative to DC with the AST values lower than that of NC. Like for ALT, administration of the crude extract and the fractions resulted in the lowering of the diabetes induced elevation of ALP with the butanol fraction showing the largest decrease followed by $100 \%$ fraction, $30 \%$ fraction and then the crude extract. The $50 \%$ methanol fraction did not have any impact on the diabetes induced elevation of the liver enzymes.

Effect of Treatment on Histology of the Pancreatic Tissues: The photomicrographs of the liver for the various treatment groups is shown in Figures 3-10. Section of the liver of NC rats (fig 3) showed a preserved architecture with the hepatocytes having abundant cytoplasm with prominent nuclei and nucleoli. The sinusoid spaces were only slightly dilated. The bile duct, hepatic artery and portal vein were intact. The livers of the untreated diabetic rats (Fig 4) while also showing a preserved architecture, had swollen hepatocyte with mild inflammatory infiltrates and prominent round to oval basophilic nuclei with some nuclei vacuolated. The cytoplasm was very eosinophilic and showed micro vesicular steatosis. The sinusoid were very dilated and congested.

The livers of treated rats (fig 5-10) showed a restoration of the integrity of the hepatocytes, and thus reversal of hepatotoxicity, to various degrees although mild mononuclear cellular infiltrates (MIF) were seen in the standard drug, crude and $30 \%$ fractions while mild vesicular steatosis and mild reversible cellular injury were seen in $100 \%$ fraction. The livers of the butanol treated rats showed only mildly swollen hepatocytes with distinct cellular outline, moderate eosinophilic cytoplasm and prominent basophilic nuclei more like the NC livers.

Increased production of free radicals especially reactive oxygen species (ROS), occasioning diabetes, may ultimately result in destruction of some vital organs of the body (Halliwell \& Gutteridge, 1989; Robertson, 2004; Moussa, 2008). Work in our laboratory and elsewhere (Akah and Okafor, 1992; Igile et al., 1995; Nwanjo and Nwokoro, 2005; Ebong et al., 2006; Ong et al., 2011; Atangwho et al., 2012) has shown the crude Vernonia amygdalina extract to have antihyperglycemic and antidiabetic activity.It has further been shown to protect the liver against diabetes induced hepatotoxicity (Ojiako and Nwanjo, 2006; Efiong et al., 2013). This study sort to establish the active fraction(s) of the crude Vernonia amygdalina extract responsible for reversing the diabetes induced hepatotoxicity as a prelude to standardizing the use of the plant in the treatment of diabetes.

All fractions reversed the diabetes induced hyperglycemia. This is consistent with our earlier work (Ugoanyanwu et al., 2015). Reversal of hyperglycemia is due to hypoglycemic phytochemicals which have been reported to include flavonoids, alkaloids, saponin, tannins, and cardiac glycosides (Hikino and Kiso, 1988; Swanston-Flat et al., 1990). Our earlier work (Ugoanyanwu et al., 2015) has shown the various fractions to have a 
preponderance of one or more of these phytochemicals. There was a preponderance of flavonoids in the $30 \%$ methanol fraction, glycosides in the $100 \%$ methanol fraction and saponins in the $50 \%$ methanol and butanol fractions. The mechanism by which these phytochemicals reversed the pancreatic damage may have been through the arrest or scavenging of free radicals responsible for the pancreatic lesion thereby enhancing regeneration of pancreatic islet cells and thus production of insulin (Ebong et al., 2006; Ong et al., 2011; Atangwho et al., 2012).

Induction of diabetes resulted in increased levels of the liver enzymes in the serum signifying hepatotoxicity. This was confirmed by the photomicrograph of the liver of the diabetic rats which revealed microvesicular steatosis, hypertrophy of hepatocytes with highly eosinophilic cytoplasm. There was loss of the usual concentric arrangement of hepatocytes, accumulation of lipid droplets, and lymphocytic inflammatory infiltrates. As explained earlier, increased reactive oxygen species occasioning diabetes may be responsible for the destruction of the liver. Hyperlipidemia, due to the increased influx of fatty acids into the liver induced by hypoinsulinaemia, could be one of the factors that accounted for fatty liver formation. Liver cell damage in diabetes is thought to increase permeability causing cytosolic isoenzymes to spill into the sinusoids and then the peripheral blood vessels. The damage of the liver cells is also responsible for the highly eosinophilic cytoplasm.

Fig.1 Fasting blood glucose in the various experimental groups.

Values are expressed as mean $\pm \mathrm{SEM}, \mathrm{n}=6$.

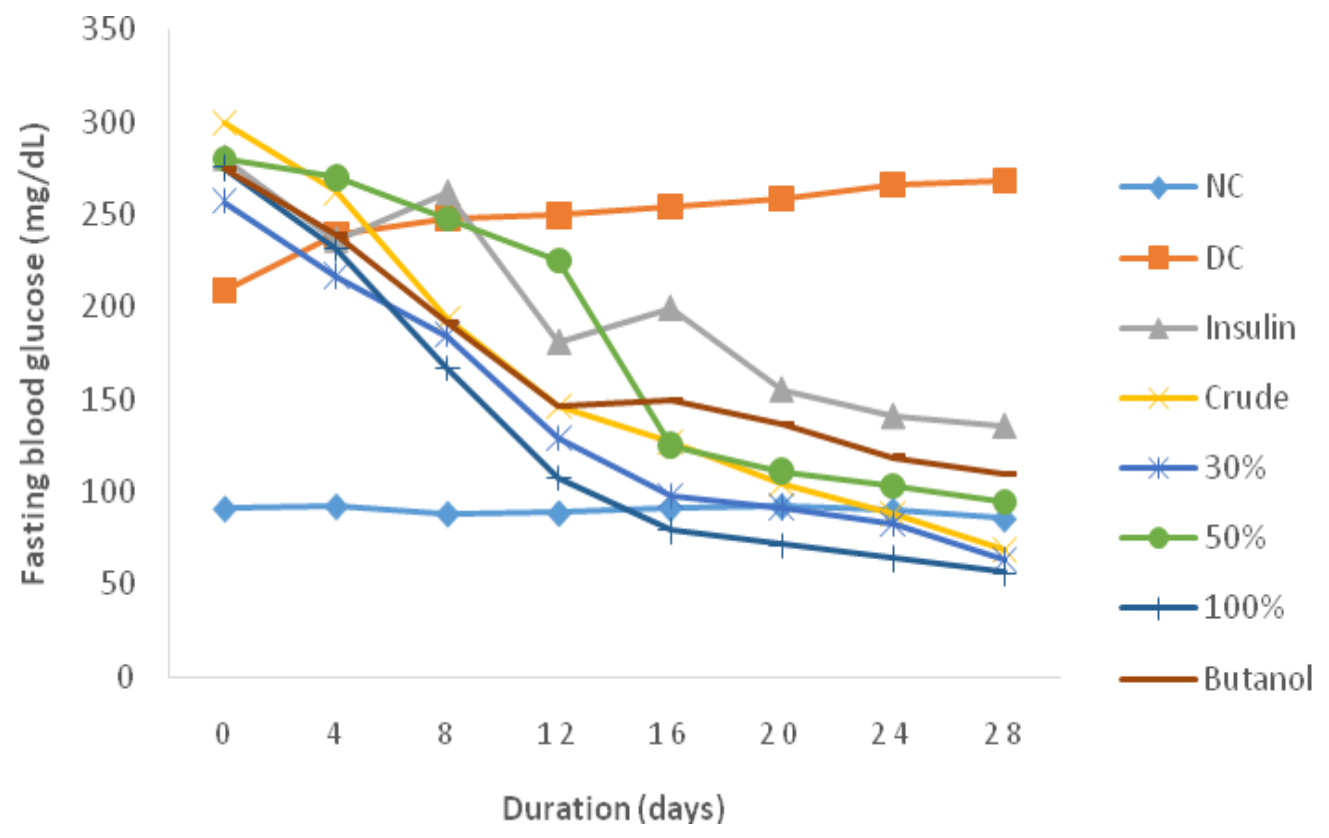


Fig.2 The effect of the various treatments on the serum levels of the liver enzymes. Values are expressed as mean $\pm \mathrm{SEM}, \mathrm{n}=6$.

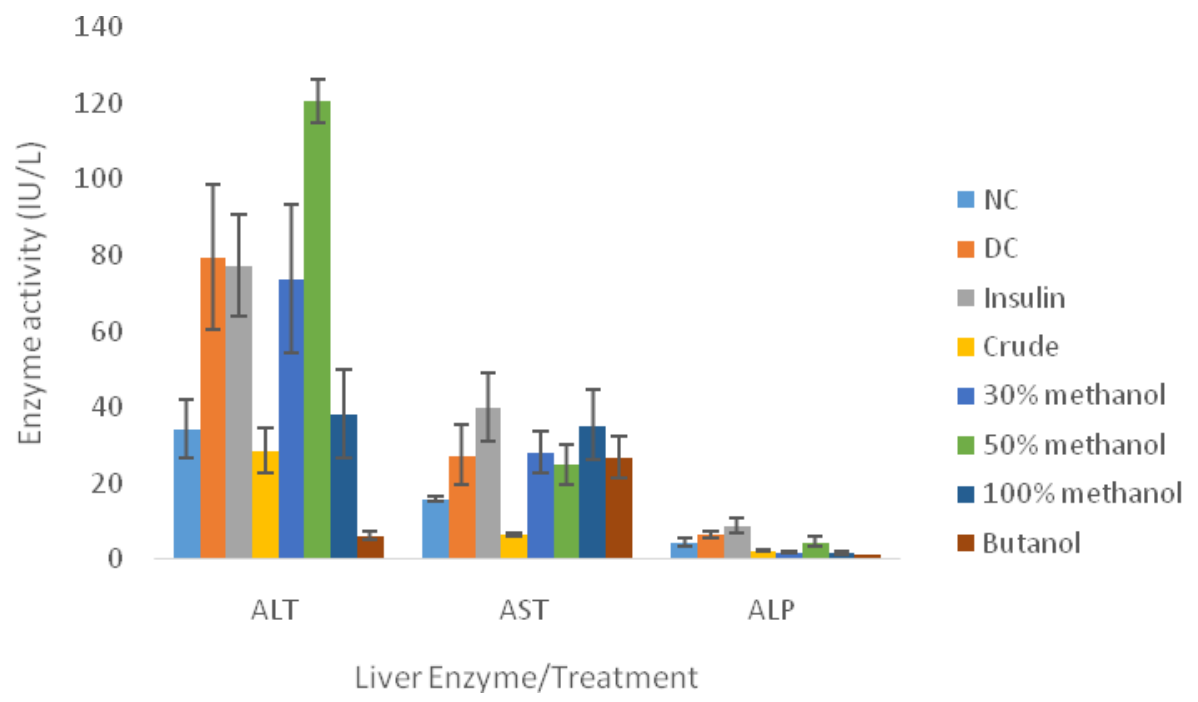

Fig.3 Photomicrograph of Normal Control Rat Liver (x 400)

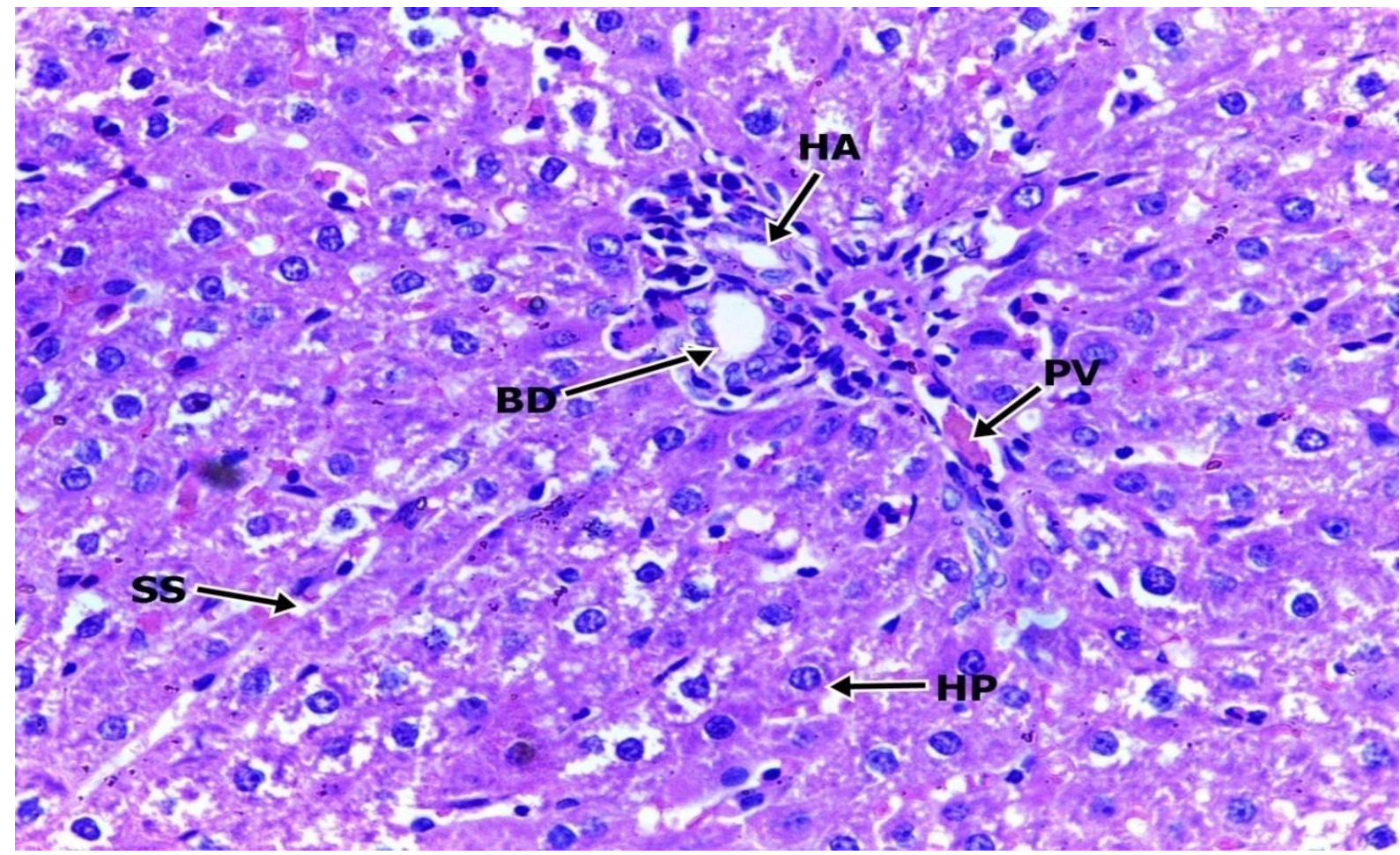

Section of the liver with a preserved architecture consisting of a central vein and hepatocytes radiating outward from it. The hepatocytes have abundant cytoplasm with prominent nuclei and nucleoli. The sinusoid spaces are only slightly dilated. The bile duct, hepatic artery and portal vein are intact.

[HA=Hepatic artery; $\mathrm{PV}=$ Portal vein; $\mathrm{HP}=$ hepatocyte; $\mathrm{BD}=$ Bile duct; $\mathrm{SS}=$ sinusoid space ] 
Fig.4 Photomicrograph of Diabetic Rat Liver (x 400)

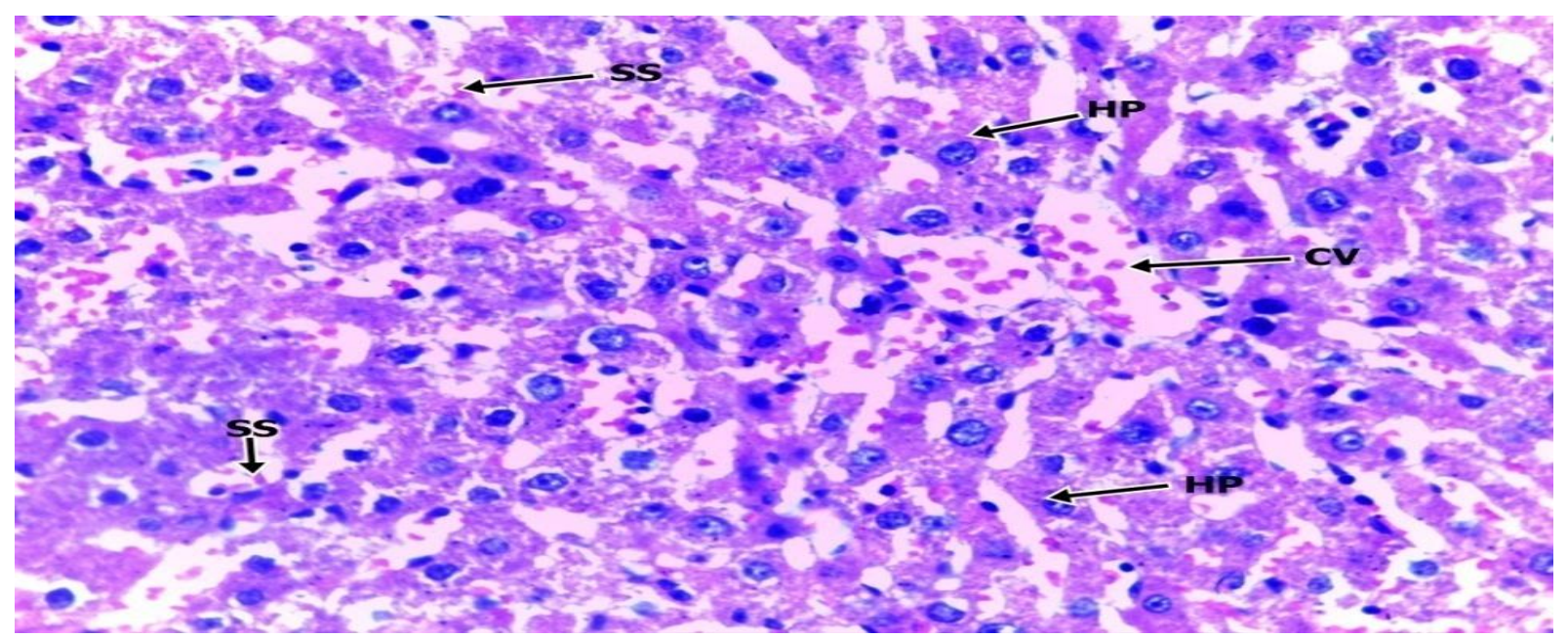

Section of the liver showing a preserved architecture with hepatocytes radiating outward. The hepatocyte are swollen with prominent round to oval basophilic nuclei with some nuclei vacuolated. The cytoplasm is very eosinophilic and shows micro vesicular steatosis and the sinusoid are very dilated and congested. The portal triad consist of portal vein, bile duct and hepatocytes with mild inflammatory infiltrates. [SS=sinusoid space; HP=hepatocytes; $\mathrm{CV}=$ central vein]

Fig.5 Photomicrograph of Insulin Treated Rat Liver (x 400)

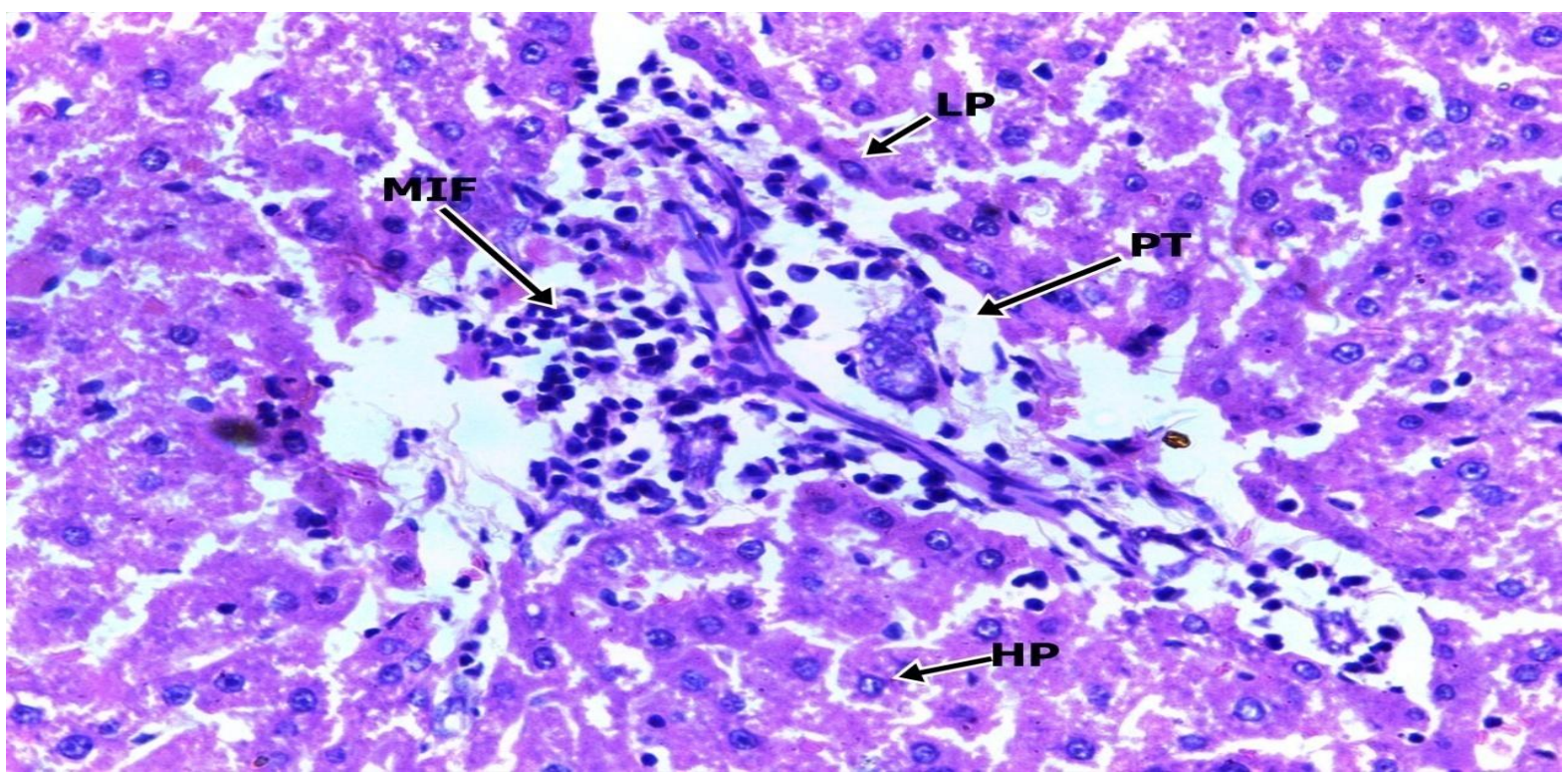

Section of the liver with a preserved architecture consisting of a central vein and hepatocytes radiating outward from it. The sinusoid spaces are dilated. The hepatocytes have moderate eosinophilic cytoplasm and basophilic oval nuclei. The portal area consists of mild mononuclear cellular inflammatory cells with intact limiting plates. The bile duct, hepatic artery and portal vein are intact. [LP=Limiting plate; $\mathrm{MIF}=$ Mononuclear cellular infiltrates; HP=Hepatocytes; PT=Portal tract] 
Fig.6 Photomicrograph of VA Crude Extract Treated Rat Liver (x 400)

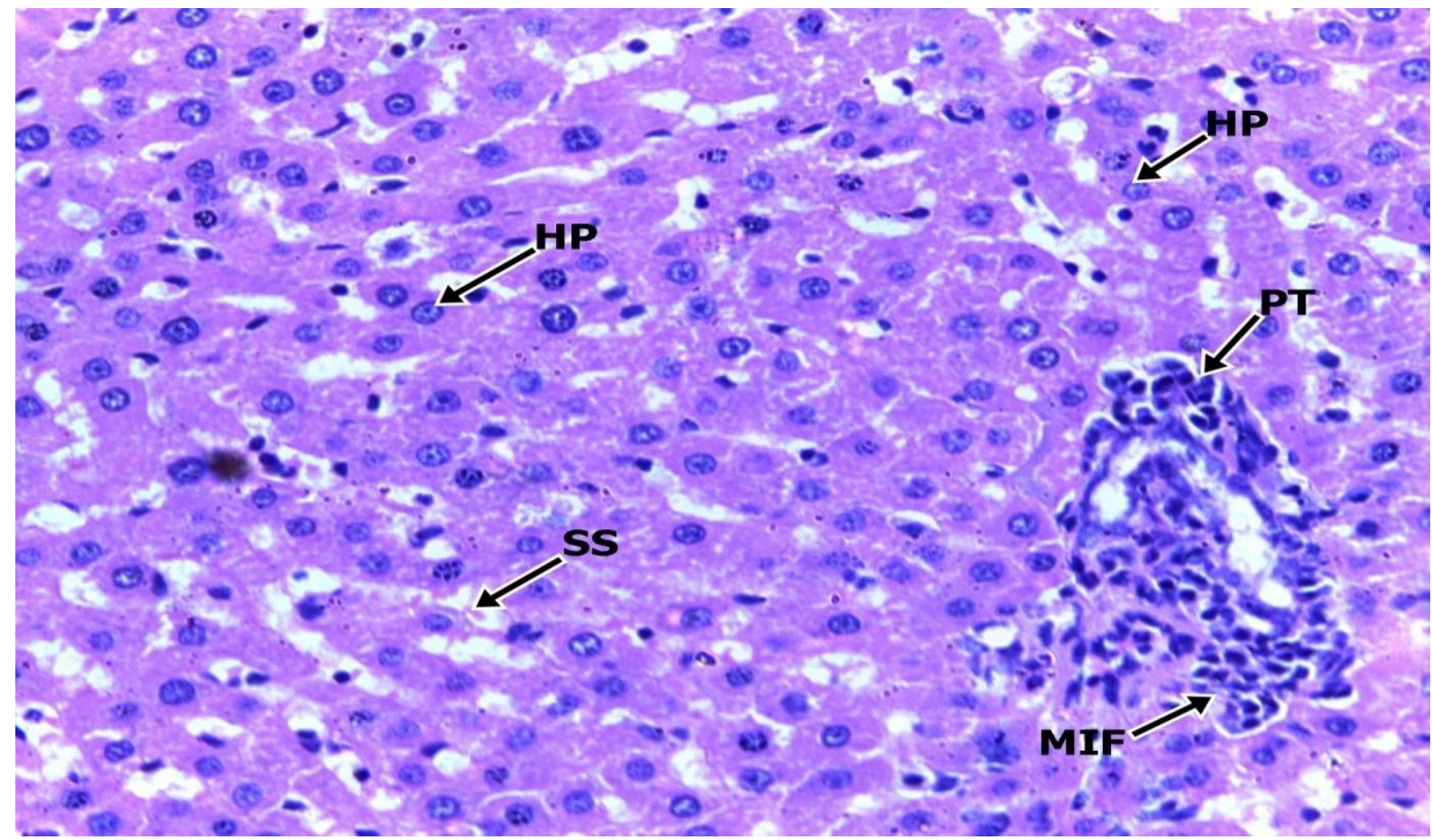

Section of the liver with a preserved architecture consisting of a central vein and hepatocytes radiating outward from it. The hepatocytes have abundant cytoplasm with prominent nuclei and nucleoli. The portal area consists of mild mononuclear cellular inflammatory cells with intact limiting plates. The sinusoid spaces are dilated. The bile duct, hepatic artery and portal vein are intact.

[HP=Hepatocyte; PT=Portal tract; MIF=Mononuclear cellular infiltrates; SS=Sinuosoidal space $]$

Fig.7 Photomicrograph of 30\% Methanol Fraction Treated Rat Liver (x 400)

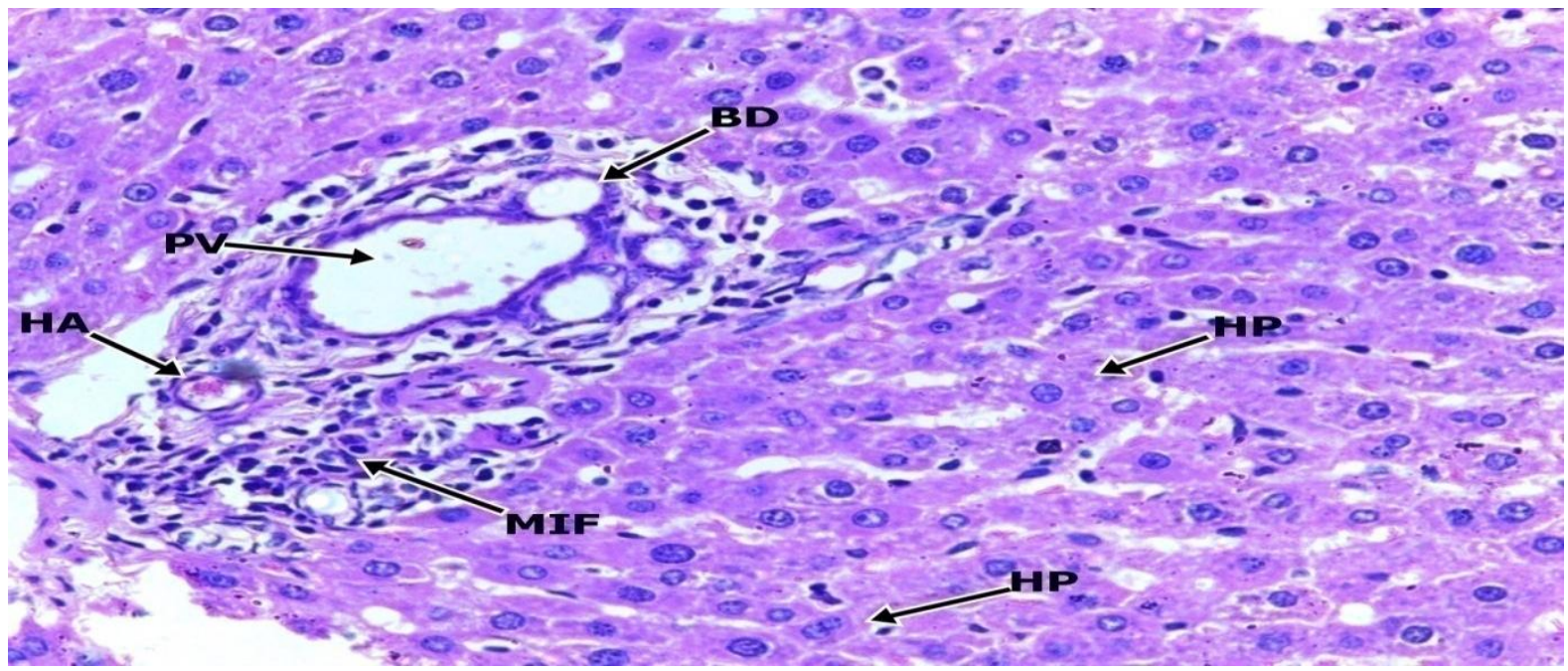

Section of the liver with a preserved architecture consisting of a central vein and swollen hepatocytes radiating outward. The hepatocytes have moderate eosinophilic cytoplasm and prominent basophilic nuclei. The portal area consists of bile duct, hepatic artery and portal vein with intact limiting plates. There is mild mononuclear cellular infiltrates. The sinusoid spaces are narrowed.

[BD=Bile duct; $\mathrm{HP}=$ hepatocyte; MIF=Mononuclear cellular infiltrates; $\mathrm{HA}=$ Hepatic artery; $\mathrm{PV}=$ Portal vein] 
Fig.8 Photomicrograph of 50\% Methanol Fraction Treated Rat Liver (x 400)

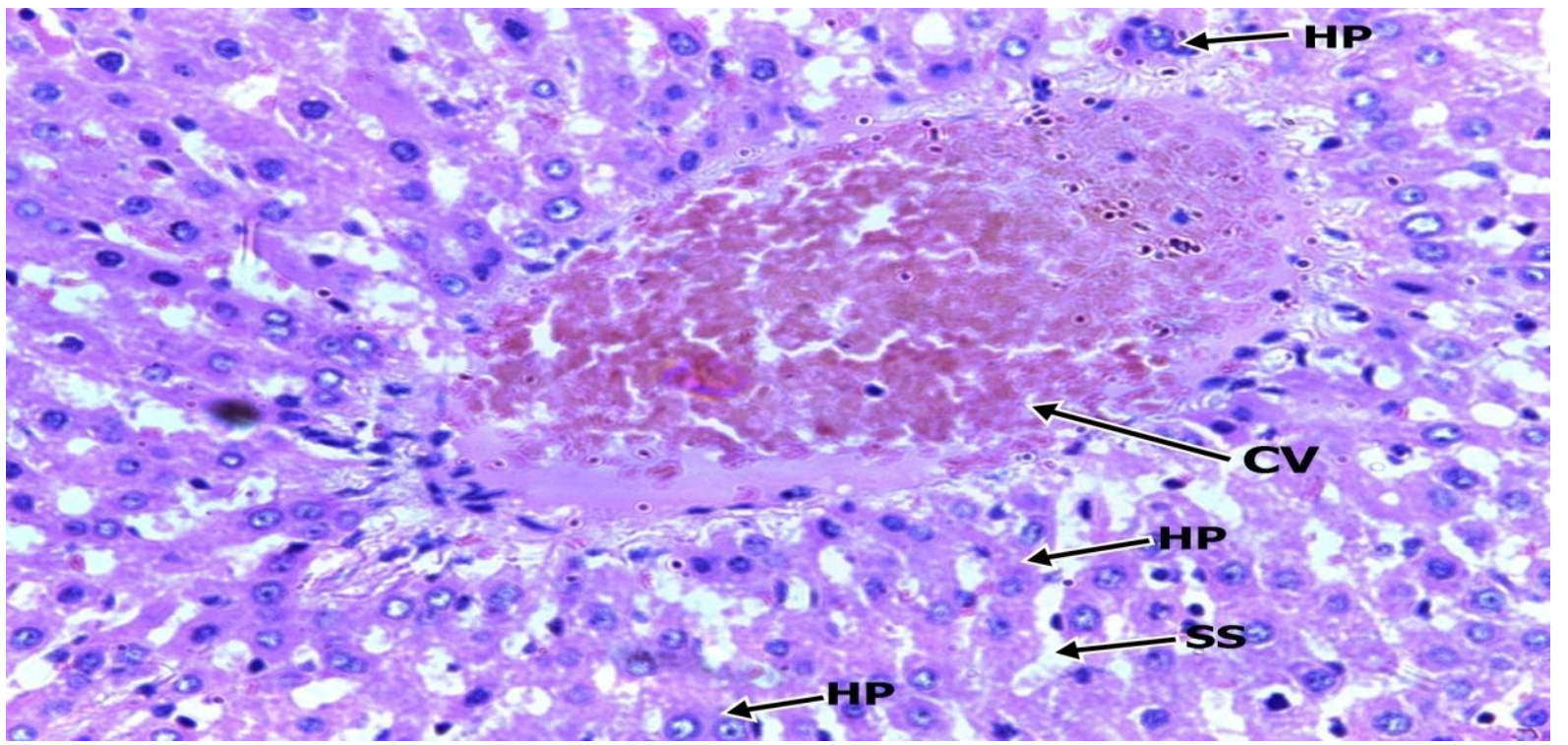

Section of liver tissueshows congested central veins with prominent hepatocytes having distinct outline radiating outward. The sinusoid spaces are dilated. The hepatocytes have abundant eosinophilic cytoplasm and prominent basophilic nuclei with nucleoli. The portal tract consists of the bile duct, hepatic artery and portal vein with and intact limiting plates.

$[\mathrm{HP}=$ Hepatocyte; $\mathrm{CV}=$ central vein; $\mathrm{SS}=$ Sinusoid space $]$

Fig.9 Photomicrograph of 100\% Methanol Fraction Treated Rat Liver (x 400)

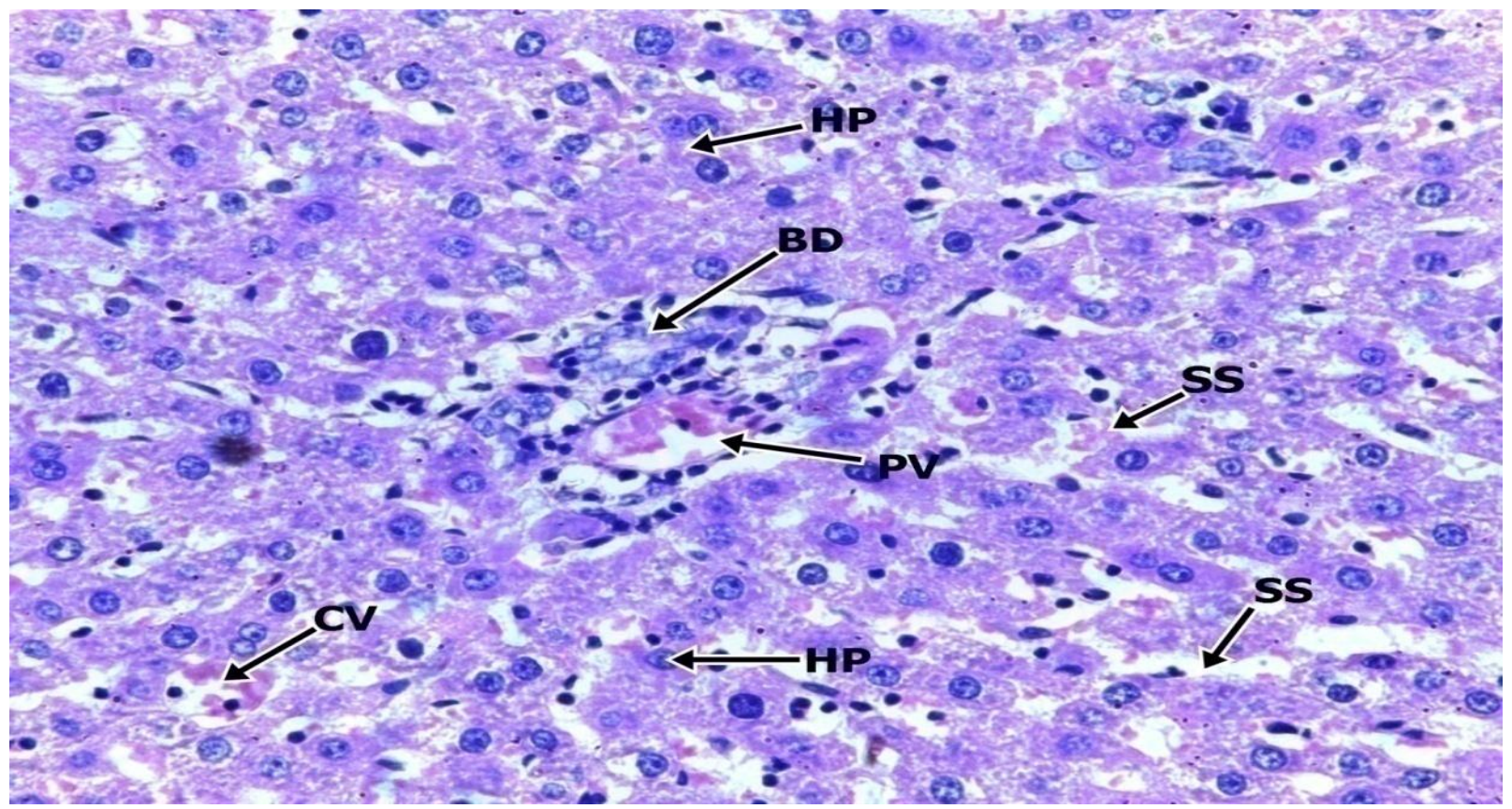

Section of liver tissue shows prominent hepatocytes with abundant cytoplasm and mild micro vesicular steatosis. The sinusoidal spaces are only slightly dilated and congested. The portal area contains the bile duct, hepatic artery and portal vein. Mild reversible cellular injury.

[HP=Hepatocyte; $\mathrm{BD}=$ Bile ducts; $\mathrm{SS}=$ Sinusoid space; $\mathrm{PV}=$ Portal vein; $\mathrm{CV}=$ central vein $]$ 
Fig.10 Photomicrograph of Butanol Fraction Treated Rat Liver (x 400)

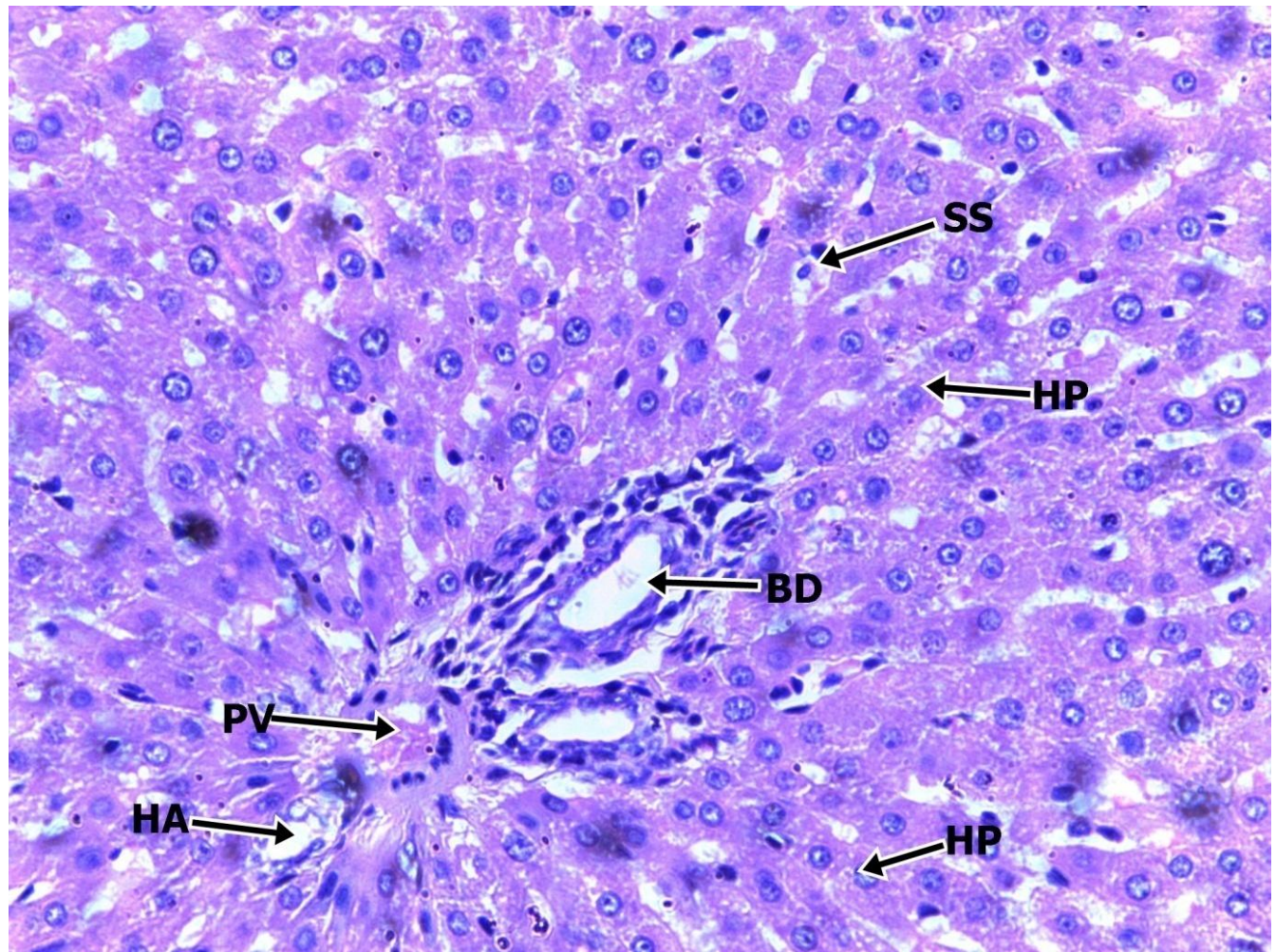

Section of the liver with a preserved architecture consisting of mildly swollen hepatocytes with distinct cellular outline, moderate eosinophilic cytoplasm and prominent basophilic nuclei. The portal area consists of the portal vein, hepatic artery and bile duct with intact limiting plates. The sinusoid spaces are only slightly dilated.

[HP=Hepatocyte; $\mathrm{BD}=$ Bile duct; $\mathrm{SS}=$ Sinusoid space; $\mathrm{HA}=$ Hepatic Artery; $\mathrm{PV}=$ Portal vein $]$

There was significant reductions in the levels of liver enzymes in the serum relative to DC on treatment with the crude leaf extract, $30 \%$ (flavonoid rich) and 100\% methanol (glycoside rich), and butanol fractions (saponin rich). The hepatoprotective effect of crude extract of Vernonia amygdalina is in consonance with earlier work in our laboratory (Atangwho et al., 2012; Efiong et al., 2013). The ability of the flavonoids, glycosides and saponin to ameliorate partly or completely the liver damage lies in their antioxidant properties (Saxena and Kishore, 2004). The antioxidant properties helps to scavenge the diabetes induced reactive oxygen species or stops its generation process. Thus the mechanism by which these phytochemicals reversed the liver damage may have been through the arrest or scavenging of free radicals responsible for the liver damage. This observation was confirmed by the histological studies which showed regeneration of the liver, albeit partial, in the diabetic rats treated with crude extracts and the 30 and $100 \%$ methanol and butanol fractions.

Of all the fractions, the saponin-rich butanol fraction on balance showed a better amelioration of diabetes induced hepatotoxicity than the crude extract suggesting that it could effectively replace the crude extract in the amelioration of hepatotoxicity. Furthermore, it will be more amenable to standardization than the crude plant extract. 
A paradox in our observation was the insignificant effect, on balance, of the equally saponin rich $50 \%$ fraction on lowering the diabetes induced elevation of liver enzymes in the serum. This is indicative that an additional factor in the butanol fraction may also be responsible or contributory to the observed hepatoprotective effect. It is a subject for further study.

In conclusion this work has shown that the butanol fraction with its relative abundance in saponins and to a lesser extent the flavonoid rich $30 \%$ methanol fraction and glycoside rich $100 \%$ methanol fractions, can reverse the STZ induced destruction of the liver occasioning the induction of diabetes. This butanol fraction can thus be an effective supplement in the formulation of a dose regimen for the management of diabetes induced liver damage. As well as being more amenable to standardization compared to the crude extract, the fractionation is a first step towards elucidation of the specific active principle(s) involved in amelioration of diabetes induced hepatotoxicity.

\section{Competing Interests}

The Authors affirm that there is no conflict of interest in the publication of this article.

\section{Ethical Approval}

All authors hereby declare that the research has been determined exempt from review by the University animal research or ethics review committee and that the principles of laboratory animal care were followed.

\section{References}

ADA (American Diabetes Association). 2005. Diagnosis and classification of diabetes mellitus. Diabetes Care, 28(suppl. 1):S37-S43.
Akah, P.A. and Okafor, C.I. 1992. Hypoglycaemic effect of Vernonia amygdalina (Del) in experimental rabbits. Plant Med. Res., 1: 6-10.

Akerele, O. 1993. Summary of WHO guidelines for the assessment of herbal medicines. HerbalGram, 28: 13-19.

Asuquo, O.R., Edet, A.G., Mesembe, O.E., Atangwho, J.I. 2010. Ethanolic extracts of Vernonia amygdalina and Ocimum gratissimum enhance testicular improvement in diabetic Wistar rats. Int. J. Alternative med., 8(2).

Atangwho, I.J., Ebong, P.E., Eyong, E.U., Asmawi, M.Z., Ahmad, M. 2012. Synergistic antidiabetic activity of Vernonia amygdalina and Azadirachta indica: Biochemical effects and possible mechanism. J. Ethnopharmcol., 141(3): 878-887.

Ebong, P.E., Atangwho, I.J., Eyong, E.U., Ukwe, C., Obi, A.U. 2006. Pancreatic beta cell regeneration: A prabable parallel mechanism of hypoglycemic action of Vernonia amygdalina Del. and Azadirachta indica. In the Proceeding of the 2006 Int. Neem Conference. pp: 838.

Efiong, E.E,. Igile, G.O., Mgbeje, B.I.A., Out, E.A. and \& Ebong, P.E. 2013. Hepatoprotective and antidiabetic effect of combined extracts of Moringa oleifera and Vernonia amygdalina in streptozotocin-induced diabetic albino Wistar rats. J. Diabetes and Endocrinol., 4(4): 45-50

Ejere, V.C., Chukwukezie, C.E., Nnamodu, E.I., Chukwuka, C.O., Echi, P.C., Ugwu, G.C., Odii, E.C., Ejim, A.O. 2015.Effect of Vernonia amygdalina ethanolic root extract on the hepato- and nephron-protective properties of albino rats (Rattus novergicus). Adv. Life sci. Technol., 30: 34-40.

Halliwell, B., Gutteridge, J.M.C. 1989. Free Radicals in Biology and Medicine. 2nd edition. Oxford: Clarendon Press.

Hikino, H., Kiso, Y. 1988. Natural products for liver diseases in Economic and 
medicinal plant research. Vol 2. London: Academic press. pp 39-72.

Igile, G.O., Wieslaw, O., Burda, S., Jurzysta, M. 1995. Nutritional assessment of Vernonia amygdalina leaves in growing mice. J. Agric. Food Chem., 43: 21622166.

Kunle, O.F., Egharevba, H.O. and Ahmadu, P.O. 2012. Standardization of herbal medicines - A review. Int. J. Biodiversity and Conservation, 4(3): 101-112.

Lorke, D. 1983. A new approach to practical acute toxicity testing. Arch. Toxicol., 54: 275-287.

Mgbeje, B.I.A., Ugoanyanwu, F.O., Igile, G.O., Ebong, P.E. 2016. Ameliorative impact of phytochemical fractions of Vernonia amygdalina leave extracts on male sex hormone levels and testicular integrity in streptozotocin-induced diabetic albino Wistar rats. World J. Pharmacy and Pharmaceutical Sci., 5(5): 120-132.

Moussa, S.A. 2008. Oxidative stress in diabetes Mellitus. Romanian $J$. Biophys., 18(3): 225-236.

Nwanjo, H.U., and Nwokoro, E.A. 2005. Antidiabetic and biochemical effects of aqueous extract of Vernonia amygdalina leaf in normoglycaemic and diabetic rats. J. Innovative Life Sci., 7: 6 - 10.

Ojiako, O.A. and Nwanjo, H.U. 2006. Is Vernonia amygdalina hepatotoxic or hepatoprotective? Response from biochemical and toxicity studies in rats. Africa J. Biotechnol., 5(18): 1648-1651.

Ong, K.W., Hsu, A., Song, L., Huang, D., Kwong, B., Tan, H. 2011. Polyphenols- rich Vernonia amygdalina shows antidiabetic effects in streptozotocin induced diabetic rats. $J$. Ethnopharmacol., 133: 598-607.

Rang, H.P., Dale, M.M. 1991. The Endocrine System of Pharmacology. UK: Longman Group Ltd.; pp.504-508.

Robertson, R.P. 2004. Chronic oxidative stress as a central mechanism for glucose toxicity in pancreatic islet beta cells in diabetes. J. Biol. Chem. 279(41): 42351-42354.

Saxena, A., Kishore, V.N. 2004. Role of selected medicinal Indian plants in management of type 2 diabetes: A review. J. Alternat. Complement. Med., 10(2): 369-378.

Shaw, J.E., Sicree, R.A., Zimmet, P.Z. 2010. Global estimates of the prevalence ofdiabetes for 2010 and 2030. Diabetes Res. Clin. Pract., 87: 4-14.

Swanston-Flat, S.K., Day, C., Bailey, C.J., Flatt, P.R. 1990. Traditional plant treatment for diabetics: Studies in normal and STZ diabetic mice. Diabetologia. 33:462-464.

Ugoanyanwu, F.O., Mgbeje, B.I.A., Igile, G.O. and Ebong, P.E. 2015. The flavonoid-rich fraction of Vernonia amygdalina leaf extract reversed diabetes-induced hyperglycemia and pancreatic beta cell damage in albino Wistar rats. World J. Pharmacy \& Pharmaceutical Sci., 4(10): 1788-1802.

Wild, S.H., Roglic, G., Green, A., Sicree, R., King, H. 2004. Global prevalence of diabetes: estimates for the year 2000 and projections for 2030. Diabetes Care, 27(10): 2569.

\section{How to cite this article:}

Bob I.A. Mgbeje, Terungwa A. Kalana, Flora O. Ugoanyanwu and Patrick E. Ebong. 2016. Effect of Phytochemical Fractions of Vernonia amygdalina on Liver of STZ Induced Diabetic Male Wistar Rats. Int.J.Curr.Microbiol.App.Sci. 5(11): 656-667. doi: http://dx.doi.org/10.20546/ijcmas.2016.511.077 